\section{Linfoma T angioinmunoblástico: caso clínico y revisión de la literatura}

\section{Sr. Director:}

El linfomaT angioinmunoblástico (LTAI) es una variante de linfoma de células $\mathrm{T}$ periférico. Representa el $4 \%$ de todos los linfomas, y el $20 \%$ de los linfomas T. Se caracteriza por un borramiento parcial o difuso de la arquitectura de los ganglios linfáticos, con una proliferación marcada de las vénulas poscapilares de endotelio alto, y de las células dentríticas foliculares (CD21+).La cápsula puede estar respetada, aunque con frecuencia hay afectación de la grasa periganglionar. También existe un infiltrado mixto de células linfoides, formado por linfocitos pequeños, células plasmáticas, y sobre todo numerosos inmmunoblastos (no son células neoplásicas), que se debe a una marcada proliferación policlonal de células B. Por último, cabe mencionar la presencia de células de Reed-Stenberg-Like (células no neoplásicas). Desde el punto de vista del inmunofenotipo (IHQ), las células neoplásicas son de estirpe $\mathrm{T}$, presenta el antígeno común leucocitario (ACL) CD45, así como antígenos T (CD2,CD3 y CD4) positivas, con los marcadores de superficie CD10, CD57 y Bcl-6 positivas. El CD45 es una glicoproteína transmembrana de 180-220 kD (1), cuyo gen se localiza en 1q31-q32, existiendo al menos 8 isoformas de CD45 producidas por el splicing alternativo de 3 de sus 34 exones (2). Las mutaciones genéticas $(\mathrm{C} 77 \mathrm{G})$ que interfieren con el splicing de CD45 podrían favorecer el desarrollo de las neoplasias del sistema inmune.

Entre las alteraciones genéticas destacan el reordenamiento de los genes de TCR (cadena gamma) en el 75\%; la presencia del genoma del VEB en el interior de los linfocitos tanto B como $\mathrm{T}$ $($ EBER1 +) $(3,4)$, y la trisomía del cromosoma 3 y/o 5 (5).

Las manifestaciones clínicas son muy variables tales como fiebre, sudoración profusa, síndrome constitucional (particularmente pérdida de peso), exantema cutáneo (6), adenopatías generalizadas, fenómenos autoinmunes, sobre todo anemia hemolítica e hipergammaglobulinemia policlonal, con inmunodepresión (mayor predisposición a las infecciones) (7).

El curso clínico generalmente es desfavorable, con una agresividad media (8), aunque en ocasiones se han descrito remisiones espontáneas, que no son predecibles por los hallazgos histológicos.

El tratamiento del LTAI no está bien establecido. Se sabe que el 30\% de los pacientes pueden presentar una remisión inicial con el empleo de corticoides, o al menos una mejoría clínica, aunque se incrementa el riesgo de infecciones; pero la mayoría de los pacientes requieren poliquimioterapia:

1. Corticoides: prednisona/metilprednisolona. Se puede considerar como primera línea de tratamiento, siempre que no haya un compromiso vital o no se trate de un paciente joven.
2. Poliquimioterapia: se considera tratamiento de segunda línea, cuando fracasan los corticoides. Aunque, debe ser tratamiento de primera línea si se trata de un paciente joven y/o hay un compromiso vital, empleando diversos esquemas como CHOP quincenal, CHOP trisemanal, CVP, IMV, etc.

En los pacientes candidatos a trasplante de médula ósea (TMO) autólogo o alogénico se debe de plantear dicha posibilidad tanto en primera línea como en la recidiva (9).

La supervivencia mediana es de 15-24 meses; y el 20\% de los LTAI desarrollan un segundo linfoma de estirpe B con VEB positivo (linfoma B de células grandes difuso).

Presentamos el caso clínico de una mujer de 31 años con hipotiroidismo primario que ingresa en Medicina Interna por presentar adenopatías cervicales, fiebre sin focalidad de 1 mes de evolución e hipergammaglobulinemia policlonal IgG (6.290 $\mathrm{mg} / \mathrm{ml}$ ). En la exploración física destaca la presencia de conglomerados adenopáticos cervicales, axilares e inguinales bilaterales y esplenomegalia a $4 \mathrm{~cm}$ de reborde costal. En la radiografía simple de tórax se objetivaban adenopatías hiliares bilaterales.

Se realiza TAC toracoabdominal que objetiva conglomerados ganglionares axilares bilaterales, adenopatías en región paratraqueal derecha, espacio prevascular, hiliares bilaterales y en región subcarinal. También existe un discreto derrame pleural bilateral. En el abdomen se demuestra un hígado discretamente aumentado de tamaño. Esplenomegalia con un diámetro longitudinal de aproximadamente unos $18 \mathrm{~cm}$.

Se demuestran también adenopatías retrocrurales, en tronco celíaco, retroperitoneales y en la raíz del mesenterio del intestino delgado conformando prácticamente un conglomerado.

También se demuestran adenopatías en pelvis menor siguiendo a los vasos ilíacos primitivos y a sus ramas, con adenopatías acompañando a los vasos ilíacos externos de hasta $37 \mathrm{~mm}$ de diámetro. Se demuestra también adenopatías inguinales bilaterales de hasta $2,5 \mathrm{~cm}$. No se demuestran lesiones óseas. Se realiza biopsia de una de las adenopatías cervicales, que presenta un parénquima ganglionar desestructurado a expensas de elementos linfoides de talla intermedia de núcleo irregular, asociados a hiperplasia venular y frecuentes microagregados histiocitarios y grupos de células plasmáticas de aspecto reactivo. La cápsula ganglionar aparece infiltrada en puntos. No se observan granulomas, ni parásitos. La IHQ muestra una proliferación de células $\mathrm{T}(\mathrm{CD} 3+)$. De forma dispersa se encuentran redes de células dentríticas foliculares $(\mathrm{CD} 21+)$, frecuentemente en situación perivascular. La investigación mediante PCR de los genes $\operatorname{IgH}$ (FR2/VDJ) y TCR-gamma (VJ) muestra únicamente reordenamientos de carácter oligo o policlonal. Se remite al CNIO y el diagnóstico final es de LTAI. La biopsia de médula ósea descarta la infiltración linfomatosa.

Se instaura tratamiento con Prednisona en Medicina Interna con mejoría clínica y se traslada a nuestro Servicio donde con el diagnóstico de LTAI estadio III-B se inicia poliquimioterapia de inducción con esquema CHOP quincenal con G-CSF (pegfilgrastim) previo a TMO autólogo en primera línea de tratamiento.

\section{P. Khosravi Shahi, V. M. Díaz Muñoz de la Espada, S. Enci- nas García}

Servicio de Oncología Médica. Hospital General Universitario Gregorio Marañón. Madrid

1. Hermiston ML, Xu Z, Weiss A. CD45: a critical regulator of signaling thresholds in immune cells. Ann Rev Immunol 2003, 21: 107-37.

2. Kung C, Pingel JT, Heikinheimo M. Mutations in the tyeosine phosphatase CD45 gen in a child with severe combined immunodeficiency. Nature Med 2000; 6: 343-345. 
3. Anagnostopoulos I, Hummel M, Finn T. Heterogeneous Epstein-Barr virus infection patterns in peripheral $\mathrm{T}$-cell lymphoma of angioimmunoblastic lymphadenopathy type. Blood 1992; 80: 180412.

4. Luzzatto F, Pruneri G, Benini E, Manzotti M, Laszlo D, Martinelli G et al. Angioimmunoblastic T-cell lymphoma with hyperplastic germinal centres and a high content of EBV-infected large B-cells carrying IgH chain gene monoclonal rearrangement. Histopathology 2005; 46: 464-6.

5. Lepretre S, Buchonnet G, Stamatoullas A. Chromosome abnormalities in peripheral T-cell lymphoma. Cancer Genet Cytogenet 2000;117:71-78.

6. Huang CT, Chuang SS. Angioimmunoblastic T-cell lymphoma with cutaneous involvement: a case report with subtle histologic changes and clonal T-cell proliferation. Arch Pathol Lab Med 2004 ;128: 22-4

7. Yamagata T, Okamoto Y, Yamagata Y, Nakanishi M, Matsunaga K, Minakata Yet al. Angioimmunoblastic lymphadenopathy with dysproteinaemia accompanied by pleural effusion. Respirology 2005; 10: $124-7$

8. Dogan A, Attygalle AD, Kyriakou C. Angioimmunoblastic T-cell lymp-homa. Br J Haematol 2003; 121: 681-91.

9. Schetelig J, Fetscher S, Reichle A, Berdel WE, Beguin Y, Brunet S, et al. Long-term disease-free survival in patients with angioimmunoblastic T-cell lymphoma after high-dose chemotherapy and autologous stem cell transplantation. Haematologica 2003; 88: 1272-8. 